\title{
Meeting Local Needs in Materials Writing
}

\author{
Rahma Al-Mahrooqi and Saleh Al-Busaidi \\ doi:10.7575/aiac.alls.v.1n.1p.91
}

Textbooks are viewed as an essential tool in ELT. Despite the abundance of commercial textbooks, very few of them seem to meet the local needs of students and teachers in a certain context, owing to certain pitfalls in the materials. When a program adopts a certain commercial textbook the teachers soon realize that they have to supplement the materials to bridge the gap between what these materials offer and the local needs. Sometimes the supplementation yields greater volumes of materials than the book itself, causing teachers and learners to lose focus. An added complexity is the fact that there are always new, more attractive titles in the market, leaving the program in a dilemma of whether to keep their old, well supplemented textbooks or to replace them with new ones and start another cycle of supplementation. The ideal solution is for a program to produce its own teaching materials. However, writing quality local materials that can compete with commercial ones can be a real challenge. It requires clear vision, creativity, commitment and team work.

The aim of this paper is two-fold: to elucidate the pitfalls of commercial textbooks, and to share the successful experience of the Language Center at Sultan Qaboos University in producing local materials for teaching writing and 
language use. We will discuss the process, the approach, the framework and students and teachers' feedback on the materials.

\section{Introduction}

The field of ELT has historically been dependent on the use of textbooks in the language classroom. Some teachers have become so textbook bound to the degree that they cannot function in the classroom without having one in hand. However, in the last two decades or so some researchers and practitioners have cast doubts on the usefulness and effectiveness of commercial textbooks as a tool for language learning. Commercial textbooks were described as "a necessary evil" (Sheldon, 1988, cited in Mukundan, 2009, p. 92). They have been attacked for a number of reasons. One of the drawbacks is that many of these textbooks are not based on research. Rather, they are based on the author's intuitions or molded on the most selling books. According to Tomlinson (1998, p. 87),

\footnotetext{
L2 learners have been disadvantaged because, until very recently, textbooks have been typically based on idealized data about the language they are teaching. Some have taught a prescriptive model of how their authors think the learners should use the target language, many have been based on the authors' intuitions about how the target language is used, most have been informed by a model of the target language based on information from reference books rather than from actual data, and nearly all have taught learners to speak written grammar.
}

In many cases, publishers are mainly driven by the amount of profit a certain textbook will generate rather than by the impact it might have on learners (Tomlinson, 1998). This has resulted in the production of textbooks that do not match the needs of the learners. 
Some publishers have realized the shortcomings and have started to produce materials as complete packages in the form of workbooks, reading resources, online materials, etc. However, this move seems to have discouraged teachers from looking for alternative authentic materials that better meet the students' needs and interests.

Another pitfall in commercial textbooks is that they use fabricated texts or planned discourse in order to control what the students learn and produce (Tomlinson, 1998). For example, learners could be asked to produce a certain text conforming to certain predicted patterns or structures that do not resemble real life discourse but yields grammatically correct utterances. Hence, such textbooks do not prepare students for real life language use. As Tomlinson (1998, p. 88) puts it, learners

need to be prepared for interaction in the real world. They need to be aware of the intensions as well as the meanings of the speakers and writers they interact with, and they need to be able to produce language which is not only accurate and appropriate but which is effective too. They need, therefore, materials which are designed to facilitate systematic progress but which at the same time provide them with encounters with the reality of target language use.

Some textbooks present texts and topics that are alien to the students in terms of culture and so they fail to engage the students affectively and cognitively. There is evidence in the literature that suggests that affective engagement plays a major role in language learning (e.g. Arnold, 1999 cited in Maley, 2009). Research has also found that utilizing students' schemata can facilitate their engagement in learning and retention of what they learn (Hui, 2009). Engagement can be 
achieved by establishing a link between the texts and the students' personal lives (Francis \& Thomas, 2010),

Most textbooks do not encourage in students the skill of noticing and discovering different grammatical forms and functions in written or spoken texts. Rather they use the approach: presentation, practice and production, with the intention of systematizing the classroom and economizing the learning (Tomlinson, 2010). Since research has proven that this approach is insufficient, other researchers and practitioners advocate the triple 'I' approach: illustration, interaction and induction (Carter, et al, 1998). This approach fosters in the learners the habit of observation which in turn facilitates their comprehension and formulation of rules.

Finally, many commercial textbooks suffer from problems related to design and layout. They tend to cram a lot of information on one page leaving little white space on the page, something that can be both daunting and taxing for the learner. Research has found that improving the visual design has a positive effect on language learning (Condone, 2005, cited in Hsu, 2010).

\section{The context}

The project took place in the intensive English language program at Sultan Qaboos University, a state-run university in the Sultanate of Oman. English is the medium of instruction exclusively in six of the nine colleges (medicine, science, agriculture, engineering, commerce and nursing) and in certain majors in the other three (arts, education and law). When admitted to the university, all students sit an English language placement test that places them into one of the five proficiency 
levels in the intensive program. The levels range from high beginner to upperintermediate and last seven to eight weeks. Students learn English for 20 hours a week in each level. They receive 6 hours of reading and vocabulary, 6 hours of listening and speaking, 6 to 8 hours of writing and language use and at some levels 2 hours of study skills. The project described in this paper targeted the writing and language use course at the first three low levels.

\section{Rationale}

In 2005 and 2006, the language center conducted a comprehensive evaluation of the intensive program curriculum. This review involved surveying the views of different stakeholders such as the language teachers, students, language program coordinators (administrators), and college faculty members. It also looked very closely at the curriculum at different levels. It specifically examined the commercial textbooks used in the intensive program. It was clear from the analysis that there was an increasing dissatisfaction with the commercial writing textbooks for several reasons, a summary of which is provided in the following paragraphs.

The center was unable to find a series that consolidates the same set of skills in a progressive developmental manner that is suitable for the different language proficiency levels that exist in the intensive program at SQU. There was no one series that catered for all the five levels. Therefore, different textbooks from different publishers were used. However, these textbooks adopted different approaches to teaching writing. Some focused on the writing process while others focused on the product. Few of them followed communicative language 
approaches to the teaching of writing. Many of them taught writing through rhetorical functions that reduced language to formulaic expressions and structures. While these approaches were easy to teach, test and learn, they encouraged memorization and hampered creativity and personal involvement in writing.

Finally, some of these books- including the ones following process oriented approaches- contained topics that were alien to the students' culture. Consequently, the students were unable to use their background knowledge and had very little input in the writing task. The students found it difficult to relate to these topics and contribute their thoughts prior to writing. In addition, a lot of time was spent explaining the topic of the model texts as well as the new vocabulary used in them leaving very little time for the actual writing task for the students. The new vocabulary to which the students were exposed via the unfamiliar topics was hard to learn, remember and use later on in either speaking or writing tasks.

Another shortcoming in commercial writing books was that the audience was not taken into consideration. The students were asked to write topics addressing an unspecified audience. The writing task also lacked a meaningful context or purpose for writing. The students wrote based on certain rubrics or prompts that were de-contextualized and so meaningless. The writing was oversimplified into sections consisting of an introduction, body paragraphs and conclusion. Not only was writing presented as a very predictable pattern consisting of a topic sentence followed by a number of sentences of supporting details but also the number of words was specified beforehand, thus limiting the students' creativity. 
Such approaches to teaching writing reinforced the idea that writing was simply a mechanical exercise of using certain formulas and structures to fulfill a certain task, rather than an act of creating and communicating meaning that utilizes background knowledge and personal experiences.

Those drawbacks of commercial textbooks which were gleaned from the curriculum review process made it quite clear that the textbooks needed to be changed and that there was a dire need to write our own materials for the writing and language use segment of the intensive program curriculum.

\section{Pre-writing stage}

The Curriculum Development Unit (CDU) considered a number of options to address the above concerns.

1. Look for alternative commercial textbooks.

2. Contract a well known publisher to produce tailor-made writing materials that suit our needs and context.

3. Write our own materials by assigning the responsibility of writing to each program within the intensive program.

4. Form one central team of writers to be responsible for producing materials for all levels.

5. Form one central team of writers to be responsible for producing materials for the first three general English levels.

After long discussions and deliberations it was decided that option 5 was the most suitable for our situation for several reasons. First, the first three levels were 
general in nature and so they were linked together. The intensive program branches into subject-specific programs at levels 5 and 6 . It was envisaged that writing materials for the first three levels of general English would help us maintain progression among the levels. It also made the material writing task more manageable in terms of time and resources.

Following the decision to focus on the lower three levels, an e-mail was sent to the Language Center staff calling for interested potential writers to apply and submit their resumes to the CDU. The call for writers specified a number of traits that the potential writers should possess to be eligible for the advertised position. The advertisement specified that a suitable candidate was one that:

1. Had an interest in writing materials.

2. Was aware of the Arab and Omani culture.

3. Was aware of various learning and teaching styles.

4. Possessed basic word processing skills.

5. Previously wrote materials that were proven to be successful.

6. Could adjust the difficulty level of texts to suit the students' proficiency level.

7. Was willing to work within a team (a team player).

8. Was ready to accept feedback from and provide feedback to others.

9. Was willing to stay in the Language Center for at least four more years after the training.

10. Did not mind teaching and writing materials for either the intensive or credit program in the Language Center. 
The advertisement noted that due to the high demand for teachers in the Language Center during the fall semester, the materials writers might be asked to teach full time during that semester only, with the materials writing project continuing in full strength in the spring semester. Although teaching full time might affect the momentum of writing, it was acknowledged that engaging in teaching courses and students at the levels the writers would be writing the materials for might serve the materials writers by keeping them updated about students' needs and classroom environment.

Each of the criteria above was made for a purpose. It was made clear that each candidate should possess most or all of the skills or traits listed above. In some cases, the candidate was requested to provide relevant and necessary documents. Each candidate was also asked to write a letter explaining why s/he felt qualified to be a member of the group and provide relevant documents to provide evidence of previous materials writing efforts.

Very few people, 17 out of over 200 teachers, felt confident to apply to join the project, probably because this was the first large-scale material writing attempt in the intensive program. A panel consisting of the Language Center administration, CDU Head, a number of Program Coordinators, was formed to evaluate the candidates using the criteria. The panel chose six writers for the task. The writers were divided into pairs, one pair per level.

In addition to the writers' team, support teams were created. This included the following: 
1. A think tank team. This consisted of the LC administration, program coordinators or administrators and CDU members and was responsible for planning and managing the project.

2. An editorial board. This consisted of program coordinators and was tasked with reviewing and editing materials produced by the writers.

3. Text bank team. This was composed of teachers who were responsible for collecting texts and pictures to be used by writers.

4. A designer. This was an Omani teacher responsible for drawing pictures and illustrations and designing materials. The reason for employing an Omani national for this position was to ensure that the artistic work is sensitive to the students' culture.

The reason for the early selection of writers was to involve them at all stages of the project and develop in them a sense of ownership and commitment to the project. This is unlike in many material writing projects where writers are given a pre-designed blueprint to follow.

\section{Background reading}

The project commenced with an extensive review of the relevant literature. Main among the reviewed literature was the results from previous analyses about students' needs and problems at the Language Centre. The team also reviewed published literature related to three main areas:

- Curriculum and course design

- The teaching of reading and writing

- Material writing 
The readings stimulated the team's interest and made members think more deeply about the different issues that could be involved in the project. The team learned about the various approaches and debates in each of the three areas. This background reading helped form a shared frame of reference among the team members.

\section{Training}

The Language Center believed that the project needed to draw from the knowledge and experience of previous projects elsewhere in the world. The project needed to involve people with experience and expertise in the field of material writing. While engaged in reading and discussions, contact was made with potential trainers. Two trainers were identified and contracted. The team formulated questions that were sent to the trainers to get their input and to give them an idea about the issues that the training workshops could or need to address. It was decided that the potential trainers needed to fulfill the following:

1. had taught English in different contexts

2. had written materials

3. had led successful material writing projects

4. was involved in material evaluation

5. had conducted training in material writing

6. had published research articles on material writing in reputed journals.

We started to search for potential trainers. The search yielded a number of names but our choice fell upon two trainers, Brian Tomlinson and Hitomi Masuhara, who met the criteria and had extensive experience in material writing and evaluation. 
The training comprised two types of sessions, one was for potential materials writers and the other session targeted the program and course coordinators (administrators). Both sessions contained both theoretical and practical aspects (hands-on training) related to language learning and materials writing.

One of the earliest tasks for the workshop participants was to examine their own beliefs about language teaching and learning in general and about how they believe people learn how to write, in particular. Each member sent their set of beliefs to the project coordinator who compiled them all. About 200 belief statements were generated by this process. These were then placed on the university website for all the members to access and comment on. The beliefs were further refined and made applicable to material writing using the following checklist:

a. Is the criterion valid (i.e. based on sound principles)?

b. Is the criterion specific?

c. Is the criterion useful?

d. Is the criterion answerable?

Below are a few examples of the beliefs:

1. I believe that language learning is more than a psycholinguistic process that occurs in the mind.

2. I believe that motivation is essential for second language learning.

3. I believe that teachers should encourage learners to use English outside the classroom. 
4. Teachers have to encourage language learners to continuously invest energy and attention in their language learning process.

5. At the low levels, students should not be fixated on error correction.

There were often controversies among the team members about certain beliefs. For example, the belief that stated: 'the materials should take into account the differences between L1 and L2' was highly debated. Some members were not in favor of including any mention of L1 in the materials because they were worried that the material would make an explicit distinction between L1 and L2 and that might disadvantage the teachers who had no or little knowledge of the Arabic language. Such inclusion of L1 could also be over-exploited by the teachers who spoke Arabic making the classes predominantly focused on Arabic rather than English.

The beliefs were classified under a number of categories: affective factors, cognitive factors, pedagogical approaches, language testing and curriculum, rubric, instructions, design, layout and so on. During the training workshops, the trainers discussed the main principles in materials writing which were then used by the members to produce sample mini units. The units were presented and commented on by the trainers and the rest of the team members. These comments helped develop a framework for the project.

The framework was based on a text-driven approach where materials development started with the identification of engaging texts rather than certain linguistic points, functions, skills or topics. A text-driven approach can be defined as using 
authentic texts as a basis for developing teaching materials. An authentic text is defined as a spoken or written text not originally intended for language teaching or learning (Tomlinson, 1998). According to this approach, writers use potentially engaging texts as a point of departure for designing learning tasks. The text is used as a stimulus to engage learners and encourage them to use the target language to accomplish certain meaningful tasks. According to Tomlinson, "a text-driven approach is a principled approach to materials development designed to help learners acquire and develop the ability to use an L2 fluently, accurately, appropriately and effectively. The motor for each unit is a carefully selected written or spoken text and this drives and connects all the activities of the unit" (Tomlinson, 2006, p. 86).

Discovery and awareness raising activities are important elements of the textdriven approach. A discovery activity can be defined as

\footnotetext{
an activity which involves learners in investing energy and attention in order to discover something about the language for themselves. Getting learners to work out the rules of direct speech from examples, asking learners to investigate when and why a character uses the model 'must' in a story, and getting the learners to notice and explain the use of ellipsis in a recorded conversation would be examples of discovery activities. (Tomlinson, 1998, p. ix)
}

Awareness raising "is an inductive approach which aims to help learners to gradually gain insights into how languages work through paying motivated attention to language in use" (Masuhara, 2006, p. 6). According to Ellis (1991), cited in Willis (1998, pp. 45-46), "consciousness raising constitutes an approach to grammar teaching which is compatible with current thinking about how 
learners acquire second language grammar rather than rely on a diet of 'practice activities' which restrict input and expect immediate accuracy in the 'production' of small items of language, we should be giving learners plenty of opportunities to discover language and systematize it for themselves before expecting them to proceduralize their knowledge and put it in use."

In addition to the overriding text-driven approach, other principles were used as a basis for the project:

- Using texts as a stimulus

- Writing as a process: brainstorming, outlining, drafting and revising

- Writing as a response: students learn to think about:

$\circ \quad$ what they are writing (text type and genre)

$\circ$ why they are writing (purpose and stimulus)

$\circ$ who they are writing for (audience)

- Guided discovery approach to grammar

- Collaborative learning (peer editing and correction)

- Critical thinking

The project aimed at producing materials that engaged students affectively and cognitively by taking into consideration their interest, ideas and feelings, building up their self-esteem and confidence as writers and leading them through a writing process that they (and hopefully the teachers too) would truly enjoy.

It was decided that the general layout of each unit would consist of the following components: 
- Readiness activity: emotional engagement and reflection

- Input text: usually one authentic or semi-authentic reading or listening text

- Reflection activities: emotional and cognitive reaction to ideas in the text. No right or wrong answers.

- Getting ready to write: setting the scene, brainstorming and planning activities on a real-life topic related to the input text

- First writing: Draft one/first attempt (not collected)

- Two or three language discovery activities: students discover language and discourse features from input text. Focus on why first and then how based on examples from the text

- Editing and revision: after every discovery activity students review and edit their own and other people's drafts. Each time students revise their writing and keep it in their file

- Final submission: the teacher only collects the final draft

- Write on: more writing tasks (optional)

- Log: students reflect on their learning.

Below is a visual representation of the framework followed in the book. As can be seen in the diagram, all the activities center around the text. The learners read a text and discuss it. Then they write in response to the ideas in the text and keep their first draft in their folder. After that, they are involved in a series of discovery activities that also spring from the input text. Once the students have made discoveries about language in use, they revisit their first draft and make changes and write a second draft. The students revise their draft after every discovery activity. 


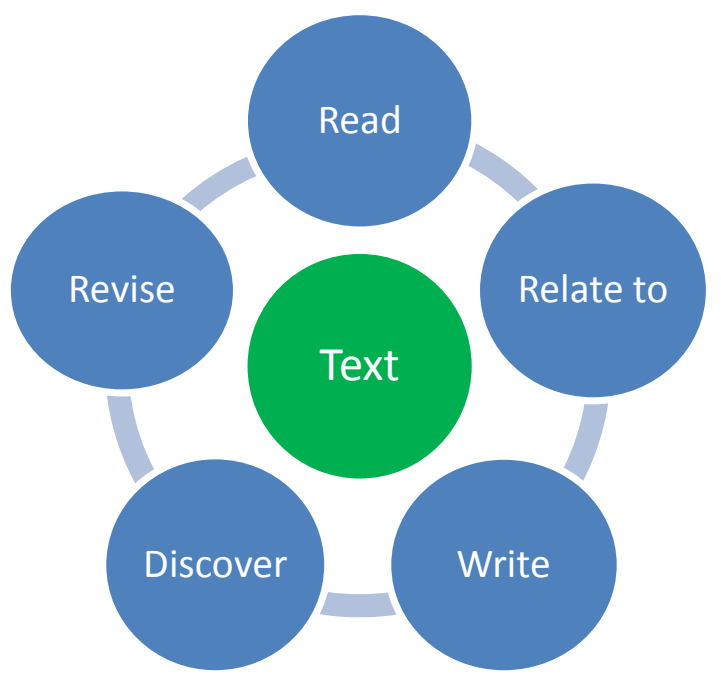

Figure 1: A visual representation of the framework

To arrive at what topic to include in the new materials, the team surveyed the students for the most interesting and popular topics they wanted to read and write about. The survey resulted in a long list of interesting topics that the writers used as a guide in their search of engaging texts.

In addition, a team was formed to create a text bank. The texts were divided into two types based on the source, academic texts coming from textbooks, website and encyclopedias and non-academic texts coming from newspapers, magazines, brochures, etc.

\section{Production cycle}

The materials were produced by writers working in pairs following the steps below:

1. Writers find an authentic text. Observe variety of genres and text types.

2. Writers develop activities following the unit outline (Draft \# 1). 
3. The unit is discussed in a meeting by the Writers Group. The Group Chair calls for a meeting and makes copies of the material for all members.

4. Writers revise the material (Draft \# 2).

5. The revised unit is sent to the Editorial Board for comments.

6. Writers revise the material based on the editors' comments (Draft \# 3).

7. The unit is sent to the designer for design work. (The Chair liaises with the designer).

8. The unit is printed for piloting.

9. Writers revise the material based on comments from piloting and the designer (Final Version).

The writers were asked to observe copyright restrictions when selecting texts. They were also asked to acknowledge all the materials they used from any external sources.

\section{Post-writing}

The materials were piloted in a very systematic manner. Prior to the piloting stage, all the aspects of piloting were well thought out, discussed and debated by the writers and editorial board. The final output was a concise document that contained the following:

1. A letter to the teacher about the piloting

2. An introduction to the project which included the objectives, the pedagogic approach, framework, teacher's role, teacher's expectations, teacher's feedback, error correction, and assessment. 
3. A feedback form in the form of a checklist containing the basic course criteria.

In addition to the overall teacher's feedback forms that were given at the end of every teaching block, there were feedback forms at the end of every unit to gather information about the students and teachers' opinions about the content and the different aspects of the unit. The feedback forms were collected and analyzed at the end of each block. The writers and the editorial board revised the materials based on the feedback.

After the second cycle of large-scale piloting, the materials were deemed to be in a good shape for publication. Therefore, a professional designer was contracted to work on the final editing and design work of the textbooks. Prior to commencing the design work, the designer was invited to visit the university and meet the project team. The purpose of the visit was to familiarize the designer with the context and give her the opportunity to interact with the writers and some of the teachers to gain a deeper insight into the needs of both the students and teachers while at the same time offer some training on material design.

\section{Evaluation}

The project involved ongoing evaluation. However, a major evaluation was conducted after the second mass piloting. The evaluation employed questionnaires, feedback forms, interviews and analysis of students' writing. The data from these sources were compiled and analyzed. The data showed that there was an overwhelming satisfaction among both students and teachers about the 
materials in the three program levels. The positive points can be summarized as follows:

- The new textbooks are an improvement from previous course books.

- They are appropriate for students' level and context.

- They use engaging tasks and topics.

- They focus on communication of meaning.

- They are user friendly and fun to teach.

- The guided discovery approach is effective.

- The process writing approach is effective.

However, some teachers expressed reservations regarding certain aspects of the course such as:

- The discrepancy between teaching and testing

- The need for teacher training on the new approach

The teachers also expressed doubts about the low level students' ability to discover language. They observed that the low level students improved the least in writing. However, the students' inability to improve might not be related to the approach used in the course book but rather to their very limited proficiency in English.

\section{Challenges}

In the opinions of the majority of those involved in the project, the students, the teachers and the writers, the project was a success. The project helped change the students' attitudes towards writing and engaged them in the writing process. It 
also seems to have made the teaching and learning of writing and grammar more fun and effective. However, this success was not achieved without surmounting a number of challenges which include:

- Not all selected writers proved to be capable of writing. This happened after the initial selection of writers and during the training workshops when the writers were asked to produce sample materials. Three writers were asked to leave the team for different reasons. Two of the writers had difficulty adapting to the approach and producing engaging materials. There was also another case of a writer who did not accept feedback and could not adapt the material to the students' needs. All of these writers were first given a chance to improve but that did not help and were eventually asked to leave the team.

- Loss of momentum. Given the lengthy and rigorous production and revision process, the project lasted for a long time (about three years), causing frustration and loss of momentum among writers at times.

- Lack of clarity about the approach. Due to the relative newness of the approach in the ELT circles in general and to the SQU context in particular, some teachers were skeptical and sometimes confused about certain aspects, such as the ones listed below:

- Some teachers were not clear about how flexible the approach was. They wondered about the order of the activities in the material (i.e. readiness, reading, reflection, writing, discovery and revision). These questions arose despite all the explanations and the rationalization that was put in the teacher's book and the workshops conducted at the beginning of every semester. 
- The role of grammar. Questions about how grammar should be taught in the course book were frequently debated among teachers who came from diverse backgrounds and had certain beliefs and ideologies about grammar instruction. While some teachers wanted to pre-teach grammar rather than let the students discover it in the text, others asked for other grammar items to be introduced in addition to those taught in each unit. Connected to the questions about grammar, the teachers also raised questions about error correction, probably surrendering to the mounting pressure from students who often insist on receiving immediate correction from the teacher rather than trying to find and correct their mistakes.

- Using the texts as models for writing. A few teachers were tempted to use the input texts as models for writing. This practice was more common at the lower levels possibly due to the students' inability to express themselves in writing.

- Use of authentic texts. One driving principle in the project was to use authentic texts. However, the team encountered a number of problems with this aspect of the project. First, many of the texts that were potentially engaging were copyright protected. These texts mostly came from newspapers and the web. The project did not have a separate budget for copyright costs and that prevented the writers from using these texts. In such cases, the writers either rewrote the texts or looked for other ones that were not copyrighted. It should be noted here that copyright restrictions have 
limited the writers' choices in finding engaging texts that seem to be abundantly available in newspapers and magazines.

- Comprehensibility level of the texts for the students. In the case where texts were found, the writers faced the dilemma of having to keep the engaging nature of the text while at the same time making it comprehensible for the students.

- Availability of release time. Given the fact that the project was situated in a primarily teaching environment there were limitations to the time available for producing materials. The writers were only able to write materials in the spring semester as in the fall semester all the teaching hours were used for teaching. This in fact prolonged the project.

\section{Conclusions}

Writing in-house materials can be a rewarding experience. Indeed, the learners' and teachers' local needs can be met more effectively. However, there are measures that have to be taken in order for this endeavor to be successful. One major point is that the project has to involve all stakeholders starting from learners to teachers and administrators. All beneficiaries need to have a say and a sense of ownership and commitment to the project. Secondly, one should know what their needs are and how they can be best met through local production of materials. As was made clear in this paper, writing in-house materials is a colossal exercise. Thirdly, planning is crucial in the success of such projects. All aspects and stages of the projects need to be carefully thought and planned. In addition, one should be aware of the potentials and resources that exit in the institution and how to best 
utilize them. Writing engaging materials is a skill that only certain people possess but the institution's role is to discover the individuals who have these skills and use them.

It is important to remember that course books are only tools which can come to life and acquire meaning in the presence of a teacher. They are not designed to be strait jackets to jeopardize teachers' ability to make decisions regarding what to exploit, keep, supplement, delete or animate (Tomlinson, 1998). 


\section{References}

Carter, C., Hudges, R., \& McCarthy, M. (1998). Telling tales: grammar, the spoken language and materials development. In B. Tomlinson (Ed), Materials Development in Language Teaching (pp. 67-89). Cambridge: Cambridge University Press.

Francis, P. \& Thomas, M. (2010). Young adult literature: arousing interest in learners towards literary texts. In S. Menon \& J. Lourdunathan (Eds.), Readings on ELT Materials IV (pp. 130-148). Malaysia: Pearson Malaysia.

Hsu, J. (2010). Emotions in the visual design of ELT materials. In S. Menon \& J. Lourdunathan (Eds.), Readings on ELT Materials IV (pp. 155-167). Malaysia: Pearson Malaysia.

Maley, A (2009). Materials writing: by the people, for the people? In J. Mukundan (Ed.), Readings on ELT Materials III (pp. 1-9). Malaysia: Pearson Malaysia.

Masuhara, H. (2006). Maths, science and English teachers in the same boat? The multidimensional awareness approach to content teaching. In J. Mukundan (Ed.), Focus on ELT Materials (pp. 1 - 11). Malaysia: Pearson Malaysia.

Mukundan, J. (2009). Are there really good reasons as why textbooks should exist? In J. Mukundan (Ed.), Readings on ELT Materials III (pp. 92-100). Malaysia: Pearson Malaysia.

Tomlinson, B. (1998). Comments on part A. In B. Tomlinson (Ed), Materials Development in Language Teaching (pp. 87-89). Cambridge: Cambridge University Press.

Tomlinson, B. (2006). The text-driven approach. In J. Mukundan (Ed.), Readings on ELT Materials II (pp. 84-101). Malaysia: Pearson Malaysia.

Tomlinson, B. (2010). Achieving change and conyinuity by humanizing your coursebook, In S. Menon \& J. Lourdunathan (Eds.), Readings on ELT Materials IV (pp. 81-92). Malaysia: Pearson Malaysia.

Willis, J. (1998). Concordances in the classroom without a computer: assembling and exploiting concordances of common words. In B. Tomlinson (Ed), Materials Development in Language Teaching (pp. 44-66). Cambridge: Cambridge University Press. 